\title{
Perceptions of undergraduates on the relationship between exposure to blended learning and online critical literacy skills
}

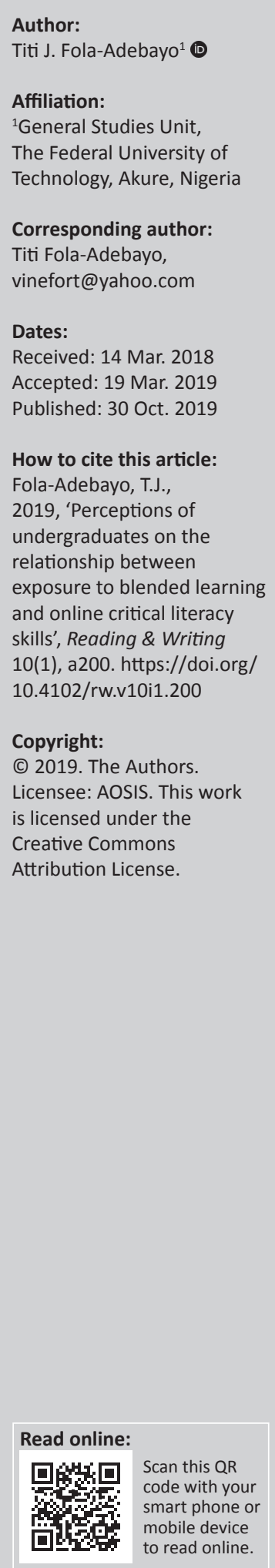

Background: Exposure to a blended experience has the potential to heighten students' online critical literacy skills, and prepare them to participate in the new online communities that emerge within a networked society.

Objectives: This article considered the perceptions of a cohort of third-year undergraduates of the Department of Communication and Language Arts, University of Ibadan, Nigeria, on the relationship between exposure to blended learning (BL) and the development of online critical literacy skills.

Method: A BL mode, which took the form of a face-to-face approach and the use of a virtual learning environment, was employed in teaching Critical Literacy, a component of the Developmental Reading Skills course designed for undergraduates of English as a second language. For 4 weeks, 80 students were trained to read web-based information critically and evaluate web pages in the Developmental Reading course, after which their perception of the relationship between exposure to BL and the development of online critical literacy skills was investigated. This work, for which data were obtained through focus group discussion and administration of a structured questionnaire, is grounded in both critical literacy (Janks 2013) and social constructivist theories (McInerney \& McInerney 2002). Frequency distribution and Pearson correlation coefficient were employed in analysing the data collected.

Results: The results revealed that the students perceived a positive relationship between exposure to BL and the development of online critical literacy skills.

Conclusion: Many of the respondents showed a preference for the BL mode, and the benefits they derived from it include: the improvement of Information and Communications Technology (ICT) skills, the acquisition of more knowledge after the class, convenient time to work and ease with self-expression.

Keywords: Digital literacy; meta-cognition; reading; second-language reading; reflective thinking.

\section{Introduction}

The last decade witnessed the rapid adoption and use of various learning management systems (LMSs) in some parts of Africa. Though researchers (Mbete \& Raisamo 2014) claim that the uptake of technology for pedagogic purposes is rather low in sub-Saharan Africa, a few exceptions exist, one of which is its use and high uptake in one Nigerian university, namely The Federal University of Technology, Akure (FUTA), Nigeria (Aborisade 2013; Fola-Adebayo 2010). Several factors led to the choice of a blended learning (BL) approach at FUTA: large classes, the need to expand students' learning spaces, the need for learner engagement, issues associated with quality assurance and acknowledgement of the fact that social contexts for learning have changed as students are no longer consumers of information but knowledge creators. The General Studies Unit at FUTA caters to the academic and communication needs of students of science and technology who have varying academic, language and Information and Communications Technology (ICT) competencies through instruction in a specially designed English for Academic Purposes (EAP) course.

Concerning pedagogic development, the FUTA EAP course has gone through three different stages. Phase 1 was patterned after the traditional grammar-translation and structuralist approach and influenced by behaviourist theory, while Phase 2 was designed along the tenets of Communicative Language Teaching (CLT), with a focus on the learner, their motivations and 
learning styles. The curriculum was focused on tasks and skills, and was problem-based in this second phase. The third phase witnessed the integration of technology in language teaching alongside the adoption of a BL approach which was underpinned by the social constructivist methods of creating innovative learning spaces, engaging the learner, fostering authentic inquiry-based learning projects and creating opportunities for student-student and student-teacher interactions (Aborisade, Fola-Adebayo \& Olubode-Sawe 2013). Adopting the BL mode allowed the use of the combination of the traditional face-to-face method and use of resources afforded by the LMS - Moodle (modular objectoriented dynamic learning environment), in this case.

The aim of the project reported on in this article was to replicate the FUTA experience in a near-similar teachinglearning context at the University of Ibadan, Nigeria, during my tenure as visiting lecturer in the Department of Communication and Language Arts (CLA) at the university. The goal was to learn more about the perceptions that undergraduate students have regarding the relationship between exposure to BL and the development of their critical literacy skills. A face-to-face approach was traditionally employed in the course delivery at this university, but I decided to trial the FUTA BL approach in the undergraduate reading course that I taught. I employed BL to teach one component of the course, namely Critical Reading and Critical Literacy. The aim was to facilitate engagement and foster the development of online critical literacy skills among the students. Though scholars (Jonas \& Burns 2010; Sharma \& Barrett 2007) claim that a conclusive definition of BL is yet to emerge, this concept typically involves the integration of two learning platforms: the traditional face-to-face and virtual environments. As such, BL in this study is defined as a learning environment that combines instruction in a faceto-face setting with instruction that involves the integration of technology in teaching.

\section{Theoretical background}

Underpinning this study are critical literacy theory (Freire 1987; Riley 2015) and the social constructivist view of learning (McInerney \& McInerney 2002; Vygotsky 1978). Riley (2015:417) claims that critical literacy 'attends to the ways that literacy is culturally, historically and politically situated'. Its common goals are highlighting socio-political issues, disrupting commonplace understandings about people and our world and promoting social justice through action (Parker 2013). Proponents of the social constructivist view of learning (McInerney \& McInerney 2002; Vygotsky 1978), who believe that learning is situation based and context bound, posit that learners are acculturated into their learning community, and they create knowledge by interacting with their social learning environment. Fox (2001), however, comments on the limitation of the social constructivist approach by arguing that constructivism does not acknowledge the role of passive perception, memorisation and the mechanical learning methods inherent in traditional lecturing. Teachers also rightly observe that knowledge is cognitively and individually constructed. In spite of this limitation of the Vygotskian perspective, the theory underscores the role of socio-cultural influences in learning.

The social constructivist theory brings to place the learnercentred experiential approach (Duffy \& Cunningham 1996), which offers learners the opportunity of examining discussions at hand from their own perspectives and building individual understanding of new ideas, concepts and information that are based on past experiences and knowledge. Although no single definition of BL exists, it is the assumption here that a BL approach incorporates several social constructivist methods in order to create innovative learning spaces. Poon (2013:274) describes BL as:

... the convergence of face-to-face settings, which are characterized by synchronous and human interaction, with Information and Communication Technology (ICT)-based settings, which are asynchronous, text-based, and involve humans operating independently.

The BL approach - which involves a paradigm shift where the emphasis moves from teaching to learning (Nunan, George \& McCausland 2000) - encourages students to learn interactively, collaboratively and at their own pace and time (Graham 2006).

The strength of this approach lies in its support of diversity, the enhancement of campus experience, operating in a global context and efficiency (Sharpe, Benfield \& Francis 2006), as well as enhanced learning outcomes for students and improved attrition rates from courses (Lopez-Perez, PerezLopez \& Rodriguez-Ariza 2011). Furthermore, through a BL approach, learners are equipped with the requisite skills and strategies for managing information in a technologyenhanced environment. In their study on academic reading in English as a Foreign Language (EFL) and modern technology, Levine, Ferenz and Reves (2000) concluded that an online networked reading environment can provide opportunities for the development of authentic reading experiences, and is important for the development of critical reading skills. In order to help learners develop critical literacy skills for reading and conducting research online, they recommend the following:

- Letting students have web-evaluation experiences.

- Applying a constructivist, learner-centred approach that will prepare students to work with ever-changing technology.

In our case, following the advice of Levine et al. (2000), students used the Internet to search for, read and evaluate web-based materials and sites on the topic assigned to the class, namely 'violence', a theme that was trending in the traditional and new media at the time, and from which groups developed different perspectives and sub-topics, such as:

- Domestic violence against women in Ibadan, South West Nigeria. 
- Effects of ethno-religious violence in Borno State, North East Nigeria.

- Causes and effects of cultism in Olabisi Onabanjo University, Ago Iwoye, Ogun State, Nigeria.

- Female genital mutilation as a form of violence against women in South East Nigeria.

- Effects of domestic violence on career women in Ibadan, South West Nigeria.

- Effects of xenophobic attacks on African nationals in South Africa.

- Effects of xenophobic attacks on the economy of South Africa.

- Causes of inter-tribal violence in Jos, Plateau State, Nigeria.

- Forms of child abuse in Ibadan, South West Nigeria.

The assignment required that, in line with the requirements of critical literacy, students generate ideas and offer solutions that hinge on social change and democratic ideals, and call for socio-political action on the type of violence they addressed in their assignment. The reading route used for these assignments was in line with the requirements of critical literacy theories, as students were showed how to be code breakers, meaning makers, text users and text analysts. As code breakers, they were instructed to read text first at surface level; as meaning makers, the instruction they received helped them to comprehend text at the level intended by the writer; and as text users, they were trained to analyse the factors that influenced the author and text. As text analysts, following Leu et al. (2004), they were trained to critically evaluate information, to distinguish between accurate and inaccurate information, important and unimportant information and biased and unbiased information, and to synthesise information and rapidly and clearly communicate solutions to others.

\section{Research questions}

This study investigated the perception of undergraduates regarding the relationship between exposure to BL and the development of online critical literacy skills. The study was guided by the following research questions:

- What, if any, benefits did students at the University of Ibadan derive from learning through a BL approach?

- What is the perceived relationship between the exposure to BL and the development of online critical literacy skills of the undergraduates?

- How did exposure to learning through the BL mode contribute to the development of the online critical literacy skills of undergraduates at the University of Ibadan?

- What are these students' perceptions of the hindrances associated with the use of Moodle?

\section{Methodology Research context and participants}

The CLA Department, which envisions itself as a centre of excellence for training in communication skills development, is located in the Faculty of Arts at the University of Ibadan. The department provides training in communication skills that are required in various settings: interpersonal, group, organisation, cross-cultural, mass and instructional communication. One of the courses offered by the department and the reading course that I taught, CLA 301, offers a presentation of fairly advanced theories and exercises on various types of reading (including flexible, inferential, critical and creative reading) and discussion of the different patterns and sources of reading difficulties at tertiary level and their corrective procedures. The course, a three-unit compulsory course with a 3-h weekly contact period, which ran for 13 weeks in one semester, was offered to approximately 80 third-year undergraduates with backgrounds in Communication and Language Arts, English, Linguistics, Library and Archival Studies, and Education. Sixty-four students (52 female, 12 male, with an age range of 19-30 years) took part in the study. More than half of the respondents $(35 ; 54.7 \%)$ fell within the age range of $16-20$ years, followed by $26(40.6 \%)$ within the range of $21-25$ years and $3(4.7 \%)$ within the range of 26-30 years. Some of these students had laptops and many had smartphones with which they browsed the Internet.

Concerning the ethical considerations of this study, the permission of the Head of Department of CLA was sought before the commencement of the study, and student volunteers whose anonymity was guaranteed were recruited among students taking the course. These were given the option of opting out of the study. The purpose of the study was explained to the participating students, who were informed that the Critical Literacy component of the course would be taught using the BL mode and that the site of The Federal University of Technology, Akure, Nigeria, would be used since the BL mode was employed in teaching EAP at FUTA. Appendix 1 (see Figure 1-A1) shows the landing page of the FUTA e-learning site.

\section{Research design and procedures}

The study utilised a mixed-method framework, as it contained both a quantitative and qualitative aspect. Focus group discussion and a questionnaire were used to gather data for this study. These instruments elicited information on: the learning mode preferred, the benefits that students believed they derived from learning through a BL mode, the perceived relationship between exposure to $\mathrm{BL}$ and the development of online critical literacy skills, the extent to which students believed that exposure to the BL mode led to the development of specific critical literacy skills, and students' perception of the hindrances associated with using Moodle. In terms of data collection, the questionnaire was administered before the focus group discussion was carried out.

\section{The blended learning approach}

The course had a $3 \mathrm{~h}$ weekly contact period which ran for 13 weeks. Moodle was introduced (https://www.learn.futa. edu.ng) midway through the semester after a substantial 
amount of work had been done on topics such as the reading process, reading comprehension, the word, word attack skill, the sentence, foregrounding, the paragraph and thoughtflow patterns. Before the students used Moodle, they received an orientation programme on the use of the resource, and they were provided with a PowerPoint presentation on how to $\log$ on to the e-learning site. Practice sessions on how to navigate the site access resources on the site and create forum posts were provided. Students formed groups of five based on their common research interest and were guided by the researcher on the use of Moodle. Links on website evaluation guides were provided in class. The students found the evaluation guide of the University of California at Berkeley (www.lib.berkeley.edu/TeachingLib/Guides/Internet/ Evaluate.html) helpful. It was reviewed with the students, who went on to read and evaluate web-based information on the topics they had chosen. Using criteria of the guide, groups evaluated and rated web pages along these scales: reliable, highly reliable and unreliable. Each group presented their discussion of the ideas generated, evaluation of web pages and group summaries to the class, and these summaries were eventually posted on the discussion forum.

The e-learning component of the course was hosted on the FUTA e-learning site, where space was created and learning materials uploaded for students' use. Only one component of the course (Critical Reading/Critical Literacy) was addressed online; this entailed weekly discussions, information from the teacher, group work and feedback from one another. Students also downloaded and uploaded assignments from and to the site and used the discussion forum.

\section{Research instruments}

As mentioned earlier, data for the study were obtained through the administration of a questionnaire and focus group discussion. For the questionnaire, a five-point Likert scale that measured students' level of agreement or disagreement was employed. Questions centred on the following: the learning mode preferred, benefits of the learning mode as far as the development of online critical literacy was concerned, students' reactions to exposure to instruction on critical literacy provided through the BL mode, how exposure to the BL mode led to the development of specific critical literacy skills, and challenges associated with the use of the FUTA learning management system. Questions asked during the focus group discussion were similar to the items in the questionnaire and students' responses were tape-recorded, transcribed and coded.

\section{Data analysis}

A total of 80 questionnaires were handed out; only 69 were returned, out of which 64 were duly completed and found usable. The qualitative data from the focus group discussion were analysed thematically, while frequency distribution and Pearson correlation coefficient (PCC) were used to analyse the quantitative data gathered with the questionnaire. The PCC was used to test for the existence of relationships between the students' exposure to the BL mode and the development of online critical literacy skills.

The PCC is defined as follows:

$$
\operatorname{Correl}(X, Y)=\frac{\sum(x-\bar{x})(y-\bar{y})}{\sqrt{\sum(x-\bar{x})^{2} \sum(y-\bar{y})^{2}}}
$$

Where:

- $\mathrm{x}=$ the 'scores' of the students in online critical literacy skills,

- $\mathrm{y}=$ the level of exposure of the students to the BL mode,

- $\bar{x}=$ the mean score for online critical literacy skills and

- $\bar{y}=$ the mean exposure of the students to the BL mode.

\section{Results \\ Preferred learning mode}

Table 1 reveals that $46(71.9 \%)$ out of the 64 students showed a preference for the BL mode, and 17 (26.6\%) indicated that they preferred the face-to-face learning mode.

\section{What benefits, if any, did the students derive from learning in a blended learning mode?}

Table 2 presents a summary of the students' responses on the benefits of BL, obtained from the questionnaire they completed. The responses with the highest values are: the improvement of ICT skill (32.4\%), the acquisition of more knowledge after the class $(18.9 \%)$, convenient time to work $(13.5 \%)$, ease with self-expression $(13.5 \%)$, the improvement of literacy skill $(8.1 \%)$ and the ability to interpret and use signal words (5.4\%). Forty-eight (75\%) students indicated that learning through the BL mode benefitted them academically, $12(18.8 \%)$ were indifferent, and $4(6.2 \%)$ students disagreed that the mode held any academic relevance for them. Forty-three (67.2\%) students indicated that they were more at liberty to enter into discussion on an online forum than in class, 6 (9.4\%) were indifferent, and 15 (23.4\%) disagreed.

TABLE 1: Preference for learning mode.

\begin{tabular}{lcc}
\hline Response & Frequency & $\%$ \\
\hline Face-to-face & 17 & 26.6 \\
BL model & 46 & 71.9 \\
No response & 1 & 1.6 \\
\hline Total & $\mathbf{6 4}$ & $\mathbf{1 0 0 . 0}$
\end{tabular}

BL, blended learning.

TABLE 2: Summary of students' responses regarding the benefits of learning in a blended learning mode.

\begin{tabular}{lcc}
\hline Benefit & Frequency & $\mathbf{\%}$ \\
\hline Convenient time to work & 5 & 13.5 \\
Ease with self-expression & 5 & 13.5 \\
Using BL is a novel idea & 3 & 8.1 \\
Acquisition of more knowledge after the class & 7 & 18.9 \\
Improvement of ICT skill & 12 & 32.4 \\
Improvement of literacy skill & 3 & 8.1 \\
Ability to interpret and use signal words & $\mathbf{2}$ & 5.4 \\
\hline Total & $\mathbf{3 7}$ & $\mathbf{1 0 0}$ \\
\hline
\end{tabular}

ICT, Information and Communications Technology; BL, blended learning. 


\section{What is the perceived relationship between exposure to blended learning and the development of online critical literacy skills?}

Table 3 shows the correlation coefficient of the perceived relationship between exposure to $\mathrm{BL}$ and the development of online critical literacy skills. A statistically positive relationship was found between students' perceived exposure to BL and the development of online critical literacy skills, as the correlation value of 0.391 was found to be significant at the 0.05 level.

\section{How did exposure to learning through the blended learning mode contribute to the development of the online critical literacy skills of undergraduates at the University of Ibadan?}

A summary of the students' responses on how exposure to learning through the BLmode contributed to the development of their online critical literacy skills is presented in Table 4. Forty-two $(65.6 \%)$ students indicated that the BL mode to a large extent contributed to the development of their critical literacy skills, 21 (32.8\%) revealed that the BL method only minimally contributed to the development of their critical literacy skills, and $1(1.6 \%)$ student claimed that the BL approach did not contribute at all to the development of their critical literacy skills.

Some of the details of the students' responses on how exposure to learning through the BL mode contributed to the development of their online critical literacy skills are presented here. Only items that ranked the highest were considered. 'Exposure to instruction on critical literacy provided through the BL mode has enabled me to focus on the main ideas in a text' ranked highest overall $(82.8 \%)$, suggesting that generally, the students were able to perform this sub-skill easily. The following items also ranked high.

Exposure to instruction on critical literacy provided through the BL mode has enabled me to:

- make use of relevant background knowledge (78.1\%)

TABLE 3: Correlation table showing the relationship between students' exposure to the blended learning mode and the development of online critical literacy skills.

\begin{tabular}{llcc}
\hline Learning mode & Variable & BL mode & Critical literacy skills \\
\hline BL mode & Pearson correlation & 1 & $0.391^{*}$ \\
& Sig. (2-tailed) & - & 0.001 \\
& $N$ & 64 & 64 \\
Critical literacy skills & Pearson correlation & $0.391^{*}$ & 1 \\
& Sig. (2-tailed) & 0.001 & - \\
& $N$ & 64 & 64 \\
\hline
\end{tabular}

Sig., significance; BL, blended learning.

*, Correlation is significant at the 0.05 level (2-tailed).

TABLE 4: Summary of respondents' views on how exposure to learning through the blended learning mode contributed to the development of their online critical literacy skills.

\begin{tabular}{lcc}
\hline Response & Frequency & $\%$ \\
\hline Large extent & 42 & 65.6 \\
Minimal extent & 21 & 32.8 \\
No extent & 1 & 1.6 \\
\hline Total & $\mathbf{6 4}$ & $\mathbf{1 0 0 . 0}$ \\
\hline
\end{tabular}

- think deeply about what I read (78.1\%)

- evaluate the passage that I am reading in print or online $(71.9 \%)$

- evaluate the content of web pages (71.9\%)

- evaluate the quality of web pages $(68.8 \%)$

- find out if the author has made use of exaggeration (65.6\%)

- draw inferences from what I am reading (65.6\%)

- be sensitive to the author's use of emotionally charged language $(65.6 \%)$

- be sensitive to the author's use of signal words and phrases $(62.5 \%)$

- check if the author has made use of propaganda (59.4\%)

- identify the author's purpose in the text (57.8\%)

- distinguish between facts and opinion stated by the author $(57.8 \%)$

- follow the author's thought-flow pattern $(57.8 \%)$

- synthesise ideas from what I read (54.7\%)

- interpret texts (54.7\%)

The ability to monitor comprehension (48.4\%) was not rated as highly as the others, suggesting that the students had not sufficiently mastered this skill.

\section{What are students' perceptions of the hindrances associated with the use of Moodle?}

In the questionnaire and focus group discussion, some of the students indicated that they had problems with Internet access and using the e-learning resource in spite of the orientation they had received.

\section{Discussion}

The results obtained regarding students' preference for the BL mode suggest that their choice of the BL platform may be linked to young people's attraction to technology, the pedagogic richness of the BL approach, the enhancement of learning it fosters and the interactive nature of ICT. These results are supported by the observation of scholars and practitioners (Morris 2014; Poon 2013) that the BL mode enhances students' learning, adds value to learning, and promotes student engagement and ubiquitous learning.

During the focus group discussion, students gave the following reasons why they preferred the BL mode:

'We live in a world that is a global village and it's network driven. I believe experimenting with technology in learning is ideal.' (Student 1, Female, 300 Level)

'It promotes the interaction with students and lecturers outside the class and makes learning not restricted to the four walls of the classroom.' (Student 2, Female, 300 Level)

Reasons regarding differences in learning style, technophobia and the stress involved in using the Internet may account for the non-preference of some students for the BL mode. Reasons for their choice of the face-to-face learning mode include the following:

'The use of technology in Nigeria can be very stressful and time-consuming as a result of poor network and it's always frustrating.' (Student 3, Male, 300 Level) 
'I will be able to interact well and directly with the lecturer and I won't have to worry about the online expenses and failures.' (Student 4, Male, 300 Level)

'It is more efficient and stress-free, while it allows for questions and clarification process. It also enables the lecturer to evaluate the students' assimilatory process by noting their non-verbal cues.' (Student 5, Female, 300 Level)

The majority of the students' claim that BL benefitted them in several ways is affirmed by researchers who claim that BL has the potential to support deep and meaningful learning, offers immense transformative potential (Fola-Adebayo 2014; Garrison \& Kanuka 2004), heightens students' learning levels, optimises their study time, reduces dropout rate and supports ubiquitous learning (Kose 2010). The responses from the focus group discussion attest to the fact that the participants considered the BL mode beneficial:

'I think it's something some set of students have been clamoring for and I think the time is right for us to embrace e-learning because I realise that most of us even outside the four walls of this faculty like to do a lot with our phones like browsing, playing games, etc., which doesn't add to intellectual capacity but an avenue came in which one can learn via phones and laptops and other gadgets; then it's very easy for us to learn and this has accorded us the privilege to learn and play. Which is a laudable effort and it should be a thing that should be employed at the faculty and even the university at large.' (Student 6, Male, 300 Level)

'It's an innovative step, it's a step in the right direction which exposes us to what we are supposed to do naturally, the use of paper and manual assignments are gradually fading, and anyone in the corporate world has to be computer savvy, because they have to be able to do some cogent work outline. So the exercises we get to do online enhance our electronic communication skills where we send mail to the lecturer and do presentations and this is like a simulation of the real environment.' (Student 7, Male, 300 Level)

'It's a wonderful initiative that I have been waiting to practice, and when the issue about the Moodle came up in class I was so excited to do anything to make it work.' (Student 8, Male, 300 Level)

Another benefit of the BL mode the students referred to was the formation of learning communities; the collaborative capabilities of the ICTs facilitate a synchronous, autonomous and collaborative learning experience and encourage learners to learn together and alone. In this way, the whole experience leads to the formation of communities of inquiry. The views expressed by some students in the focus group discussion regarding the link between $\mathrm{BL}$ and the formation of a community of inquiry is reiterated by Garrison and Kanuka (2004:97) who observed that:

Community provides the stabilizing, cohesive influence that balances the open communication and limitless access to information on the Internet. Communities also provide the condition for free and open dialogue, critical debate, negotiation and agreement - the hallmark of higher education.

Some focus group discussion participants had this to say concerning the benefits they derived from working in groups:

'There is still some fun in the groups, I had to sleep on an open roof so that I can send the assignment online when the portal wasn't connecting, and that keeps me going, that makes me continue even when the pressure was much and my group members were fantastic.' (Student 9, Female, 300 Level)

'Group work is a platform for you to develop. It builds you for the future; it builds you to become someone responsible.' (Student 1, Female, 300 Level)

'Group work exposes some people in the case that there are some people who are silent even in class they are knowledgeable and have it inside of them, group work exposes the people to share their thoughts and help in getting to create a relationship among all the group members.' (Student 2, Female, 300 Level)

While the majority of the respondents claimed that they benefitted from the use of the BL mode, others were apathetic. Technophobia, scepticism, time demands, the financial expense involved in its use, infrastructural issues, or mere resistance to change may account for the negative views they held regarding the use of BL as a learning approach. One of the students explained the challenges associated with the learning approach:

'It is a good initiative, though the Nigerian system is not yet ready to accommodate e-learning. Reason being that our Internet package is woeful because most students cannot afford to buy big data for browsing. Even if there is data, the network is not encouraging and people still have to stay up all night before they can submit their assignment.' (Student 10, Male, 300 Level).

The results of this study, which indicate a relationship between exposure to $\mathrm{BL}$ and the development of online critical literacy skills, are supported by the observation of researchers that BL leads to deep and meaning educational experiences, fosters student engagement and learning outcomes (Akyol \& Garrison 2011; Morris, 2014; Sarabadani \& Berenjian 2017), and presents a platform for dynamic interactive exchange and the development of teamwork skills development.

The claim by the majority of the students that exposure to learning through BL contributed largely to the development of their critical literacy skills can be explained by the substantial benefits a technology-supported medium offers; virtual learning environments deploy pedagogic tools that provide engagement and opportunities for enhanced learning. Researchers (Levine et al. 2000) also reveal that reading in an online networked environment facilitates the development of online critical literacy skills.

The results regarding students' perceptions of the hindrances associated with the use of Moodle are similar to the findings of researchers who reported that power failures (Okaz 2015), lack of IT knowledge and socio-economic factors (Holley \& Oliver 2010) constituted reasons why students had problems with the use of BL. The responses of the students in the current study included the following:

'Because we are making use of the Moodle, there is a big problem with the Internet access, my group and I have spent hours in a café trying to log in. And it does impinge on the time allotted to other courses, as sometimes the planned time for other courses is spent on CLA 301.' (Student 6, Male, 300 Level) 
'Logging in and network connections were my major challenges as well as [the] submission of assignments.' (Student 7, Male, 300 Level)

'I find it difficult to register or log in with [the] FUTA link platform. Thus I can't submit my individual assignment.' (Student 11, Male, 300 Level)

\section{Recommendations}

Based on the results of this study, the following recommendations are made:

- Teachers of English as a second language should include the skills of critical literacy in their curriculum. Doing this will help students understand the political and economic contexts in which texts are created, shaped and embedded, and help them fully participate in the new emerging literacies and democracies.

- Teachers should also focus on teaching the grammar and rules that attribute meanings to language and its use in political and social settings.

- Finally, teachers should endeavour to teach critical literacy at the primary level in order to facilitate critical thinking in young learners; also, training in critical literacy will help children examine texts from multiple perspectives, and enhance their reading experience at the emergent level.

\section{Conclusion}

This study investigated the perceptions of undergraduates of the Department of Communication and Language Arts, University of Ibadan, Nigeria, of the relationship between exposure to BL and the development of online critical literacy skills. The participants were trained for 4 weeks to read webbased information critically and evaluate web pages in a Developmental Reading course. Data were obtained through the administration of a questionnaire and focus group discussion. The results revealed that the majority of the students preferred the BL mode and claimed that they benefitted from it. Some of the benefits they derived include the improvement of ICT skills, the acquisition of additional knowledge after class, control over time, ease of expression, the improvement of literacy skills and formation of communities of inquiry. Furthermore, the results showed a statistically positive relationship between exposure to BL and the development of online critical literacy skills. The majority of the students indicated that the BL mode to a large extent contributed to the development of their online critical literacy skills. This study confirms the results of similar studies on the usefulness of the BL approach. Yen and Lee (2011:138), for example, highlight the relevance of the BL mode in their assertion that 'BL, thoughtfully combining the best elements of online and face-to-face education, is likely to emerge as the predominant teaching model of the future'.

The study had as its main objective the development of online critical literacy skills among the indicated undergraduates. This objective was met as the students read texts on the topic of violence, generated ideas and provided solutions which centred on the need for change, and challenged societal response to the issue they discussed. They came up with democratic ideals and called for socio-political action on the issue of violence. Of particular interest to the class was the issue of xenophobic attacks on Africans and their businesses in South Africa, and a call for socio-political action mandating the African Union and United Nations to prevail on the Government of South Africa to defend fellow Africans and their interests in their country.

\section{Future research}

Future research in this area should focus on factors that facilitate the development of online critical literacy skills and consider policy framework and practice that guide adult online literacy in selected African curricula and countries.

\section{Acknowledgements}

The assistance received, including the opportunity to use the e-learning site of The Federal University of Technology, Akure, Nigeria, for the study, and the participation of undergraduates of the University of Ibadan, Ibadan, Nigeria, are gratefully acknowledged.

\section{Competing interests}

I declare that I have no financial or personal relationship(s) which may have inappropriately influenced me in writing this article.

\section{Author's contributions}

I declare that I am the sole author of this research article.

\section{Ethical consideration}

This article followed all ethical standards for carrying out research without direct contact with human or animal subjects.

\section{Funding information}

This research received no specific grant from any funding agency in the public, commercial, or not-for-profit sectors.

\section{Data availability statement}

Data sharing is not applicable to this article as no new data were created or analysed in this study.

\section{Disclaimer}

The views and opinions expressed in this article are those of the author and do not necessarily reflect the official policy or position of any affiliated agency of the author.

\section{References}

Aborisade, P.A., 2013, 'Investigating African "digital immigrant" students' responses to Moodle resources', Higher Education of Social Science 4(3), 68-77. 
Aborisade, P.A., Fola-Adebayo, T. \& Olubode Sawe, F., 2013, 'Digital immigrant students' adoption of online community of inquiry: FUTA case study', in E. Ivala (ed.), Proceedings of the 8th International Conference on E-Learning, Cape (ed.), Proceedings of the 8th International Conference on E-Learning, Cape
Peninsula University of Technology, Cape Town, South Africa, June 27-28, 2012, Peninsula University of Technology, Cape
pp. 1-9, Academic Conferences, Reading.

Akyol, Z. \& Garrison, D., 2011, 'Understanding cognitive presence in an online and blended community of inquiry: Assessing outcomes and processes for deep
approaches to learning', British Journal of Educational Technology 42(2), 233-250. approaches to learning', British Journal of Education
https://doi.org/10.1111/j.1467-8535.2009.01029.x

Duffy, T. \& Cunningham, D., 1996, 'Constructivism: Implications for the design and delivery of instruction', in D.H. Jonassen (ed.). Handbook of research on educational communications and technology, pp. 170-198, Scholastic, New York.

Federal University of Technology Akure (FUTA), n.d., FUTA e-Learning, viewed n.d. from https://www.learn.futa.edu.ng/

Fola-Adebayo, T., 2010, 'Students' evaluation of a Moodle resource in The Federa University of Technology, Akure, Nigeria', in R. Taiwo (ed.), Handbook of research on discourse behavior and digital language structures and social interaction, vol. 2, pp. 670-686, Hershey, New York.

Fola-Adebayo, T., 2014, 'Promoting metacognitive learning using blogs in an L2 learning community', Marang: Journal of Language and Literature 24, 71-87.

Fox, R., 2001, 'Constructivism examined', Oxford Review of Education 27(1), 23-35. https://doi.org/10.1080/03054980125310

Freire, P., 1987, 'The importance of the act of reading', in P. Freire \& D. Macedo (eds.), Literacy: Reading the word and the world, Bergin and Garvey, South Hadley, MA.

Garrison, D. \& Kanuka, H., 2004, 'Blended learning: Uncovering its transformative potential in higher education', The Internet and Higher Education 7(2), 95-105. https://doi.org/10.1016/j.iheduc.2004.02.001

Graham, C., 2006, 'Blended learning systems: Definition, current trends, and future directions', in C. Bonk \& C. Graham (eds.), Handbook of blended learning: Global perspectives, local designs, pp. 3-21, Pfeiffer, San Francisco, CA.

Holley, D. \& Oliver, M., 2010, 'Student engagement and blended learning: Portraits of risk', Computers and Education 54(3), 693-700. https://doi.org/10.1016/j. compedu.2009.08.035

Janks, H., 2013, 'Critical literacy in teaching and research', Education Inquiry 4(2), 225-242. https://doi.org/10.3402/edui.v4i2.22071

Jonas, D. \& Burns, B., 2010, 'The transition to blended e-learning: Changing the focus of educational delivery in children's pain management', Nurse Education in Practice 10(1), 1-7. https://doi.org/10.1016/j.nepr.2009.01.015

Kose, U., 2010, 'A blended learning model supported with Web 2.0 technologies', Procedia Social and Behavioral Sciences 2, 2794-2802.

Leu, D.J., Kinzer, C.K., Coiro, J. \& Cammack, D., 2004, 'Toward a theory of new literacies emerging from the Internet and other ICT', in R.B. Ruddell \& N. Unrau (eds.), Theoretical models and processes of reading, 5th edn., International Reading Association, Newark, NJ.
Levine, A., Ferenz, O. \& Reeves, T., 2000, 'EFL academic reading and modern technology: How can we turn our students into independent critical readers?', The Electronic Journal for English as a Second Language 4(4), 1-9.

Lopez-Perez, M.V., Perez-Lopez, M.C. \& Rodriquez-Ariza, L., 2011, 'Blended learning in higher education: Students' perceptions and their relation to outcomes', Computers and Education 56(3), 818-826. https://doi.org/10.1016/j.compedu.2010.10.023

Mbete, J.S. \& Raisamo, R., 2014, 'A model for assessing learning management system success in higher education in sub-Saharan countries', The Electronic Journal of Information Systems in Developing Countries 61(7), 1-17. https://doi. org/10.1002/j.1681-4835.2014.tb00436.x

McInerney, D.M. \& McInerney, V., 2002, Educational psychology: Constructing learning, 3rd edn., Prentice Hall, Sydney.

Morris, N.P., 2014, 'How digital technologies, blended learning and MOOCS will impact the future of higher education', in Proceedings of eLearning, 2014, 15-18 July, Lisbon, Portugal.

Nunan, T., George, R. \& McCausland, H., 2000, 'Rethinking the ways in which teaching and learning are supported: The flexible learning centre at the University of South Australia', Journal of Higher Education Policy and Management 22(1), 85-98. https://doi.org/10.1080/713678130

Okaz, A., 2015, 'Integrating BL in higher education', Procedia-Social and Behavioral Sciences 186, 600-603. https://doi.org/10.1016/j.sbspro.2015.04.086

Parker, J.K., 2013, 'Critical literacy and the ethical responsibilities of student media production', Journal of Adolescent and Adult Literacy 56(8), 668-676. https://doi. org/10.1002/JAAL.194

Poon, J., 2013, 'Blended learning: An institutional approach for enhancing students' learning experiences', MERLOT Journal of Online Learning and Teaching 9(2), 271-288.

Riley, K., 2015, 'Enacting critical literacy in English classrooms: How a teacher learning community supported critical inquiry', Journal of Adolescent and Adult Literacy 58(5), 417-425. https://doi.org/10.1002/jaal.371

Sarabadani, Z. \& Berenjian, A., 2017, 'The role of blended learning on student performance in Biotechnology course', American Journal of Biochemistry and Biotechnology 13(3), 111-113. https://doi.org/10.3844/ajbbsp.2017.111.113

Sharma, P. \& Barrett, B., 2007, Blended learning: Using technology in and beyond the language classroom, Macmillan, Oxford.

Sharpe, R., Benfield, G. \& Francis, R., 2006, 'Implementing a university e-learning strategy: Levers for change within academic schools', Research in Learning Technology 14(2), 135-151. https://doi.org/10.1080/09687760600668503

Vygotsky, L., 1978, Mind in society: The development of higher psychological processes, Harvard University Press, Cambridge, MA.

Yen, J.C. \& Lee, C.Y., 2011, 'Exploring problem solving patterns and their impact on learning achievement in a blended learning environment', Computers and Education 56(1), 138-145. https://doi.org/10.1016/j.compedu.2010.08.012

Zaka, P., 2013, 'A case study of blended teaching and learning in a New Zealand secondary school, using an ecological framework', Journal of Open, Flexible and Distance Learning 17(1), 24-40. 


\section{Appendix 1}

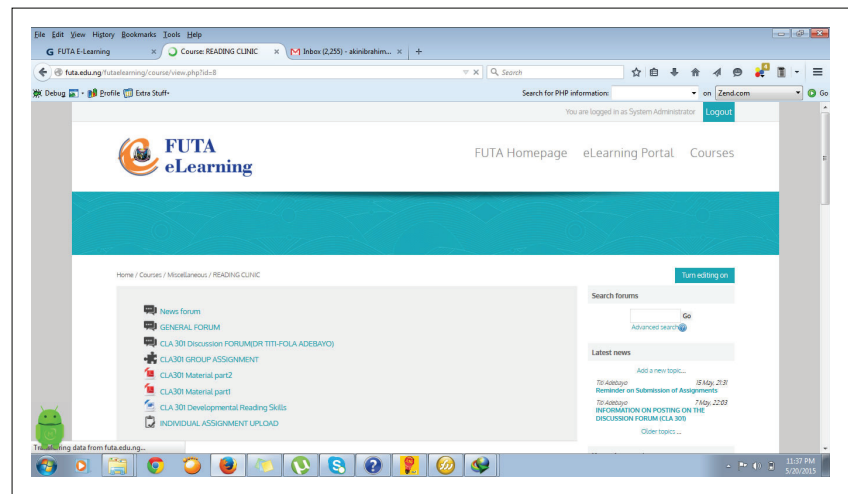

Source: Federal University of Technology Akure (FUTA), n.d., FUTA e-learning, viewed n.d. from https://www.learn.futa.edu.ng/

FIGURE 1-A1: Landing page of the FUTA e-learning site. 